\title{
Design of a Series-parallel Oil-electric Hybrid Vehicle Transmission System \\ Gong Wenzi
}

College of Automobile Engineering, Wuxi Institute of Commerce, Wuxi, Jiangsu ,China, 214153

gongwenzi1968@sina.com

Keywords: Series-parallel type; Oil-electric hybrid vehicle; One-row planet gear mechanism; Design of transmission system

\begin{abstract}
. the paper introduces the transmission system of a series-parallel oil-electric hybrid vehicle. Its drive motor, engine starting motor and generator are three-in-one, so that the structure is simplified and the cost is reduced. With no speed changer set independently, the one-row planet gear mechanism through different input conditions can realize forward stepless variable speed and reversing driving.
\end{abstract}

\section{Introduction}

Hybrid electric vehicle refers to the kind of vehicles that carry different power sources and can drive with the adoption of different power sources simultaneously or respectively according to the automobile driving needs; at present, the most common is oil-electric hybrid vehicle, that is, the engine and electric motor serve as power source. Hybrid electric vehicle according to the power system structure can be classified into series, parallel and series-parallel three categories. Of which the series-parallel hybrid vehicle could be selected automatically the electric mode, engine mode or mixed mode according to driving conditions. Although the oil-electric hybrid vehicle can't achieve zero emissions, compared with traditional internal combustion engine vehicles, it has better environmental protection, energy saving and efficiency, and will have good development trend at present and in the near future [1].

\section{System Composition and Structure}

As shown in Figure 1, the series-parallel oil-electric hybrid vehicle transmission system consists of a power battery, auxiliary storage battery, DC/DC converter, frequency converter, motor, hybrid power control unit, engine control unit, engine, one-row planet gear mechanism, clutch 1, clutch 2, brake, CAN bus, ignition lock, engine auxiliary control switch, charging interface, main reducer, differential mechanism, wheels and accelerator pedal, gear, brake, speed and other sensors.

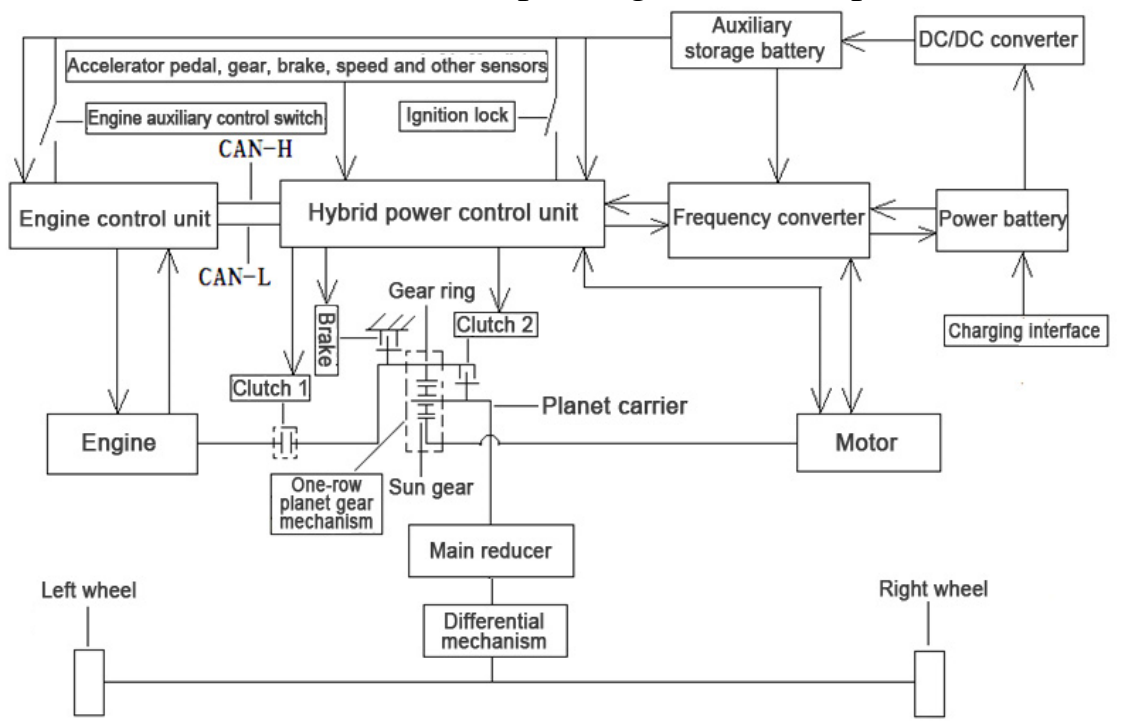

Figure 1 Schematic diagram of series-parallel oil-electric hybrid vehicle transmission system 
The functions of main parts are as shown in Table 1.

Table 1 Functions of main parts [2]

\begin{tabular}{|c|c|c|}
\hline No. & Part Name & Functions of main parts \\
\hline 1 & Power battery & $\begin{array}{l}\text { High voltage power supply provides the frequency converter and motor with } \\
\text { working power supply. At the same time, the electric energy information is fed } \\
\text { back to the frequency converter. }\end{array}$ \\
\hline 2 & $\begin{array}{c}\text { Auxiliary storage } \\
\text { battery }\end{array}$ & $\begin{array}{l}\text { Low voltage power supply, with a voltage value of } 12 \mathrm{~V} \text { provides the controllers } \\
\text { with working power supply. }\end{array}$ \\
\hline 3 & $\begin{array}{l}\text { Frequency } \\
\text { converter }\end{array}$ & $\begin{array}{l}\text { Based on the control instruction of hybrid power control unit, the speed and } \\
\text { rotational direction of the motor are controlled, and the vehicle's kinetic energy } \\
\text { can be recovered in the state of energy recovery to recharge the power battery. At } \\
\text { the same time, the frequency converter feeds back the information on voltage, } \\
\text { current, temperature, electric quantity and other technical parameters to the } \\
\text { hybrid power control unit; the hybrid power control unit adjusts and corrects the } \\
\text { control parameters, and the protection mode can also be started when necessary. }\end{array}$ \\
\hline 4 & DC/DC converter & $\begin{array}{l}\text { Converts the high voltage DC of power battery into } 12 \mathrm{~V} \text { DC, to recharge the } \\
\text { auxiliary storage battery. }\end{array}$ \\
\hline 5 & $\begin{array}{l}\text { Engine control } \\
\text { unit }\end{array}$ & $\begin{array}{l}\text { Data communication with the hybrid power control unit is carried out through } \\
\text { CAN bus, and the information on the engine's operating parameters and the } \\
\text { control instruction of the hybrid power control unit are received, to control } \\
\text { whether the engine is working and to determine the working conditions. }\end{array}$ \\
\hline 6 & Generator & $\begin{array}{l}\text { As a gasoline engine, it is started by the motor when it is necessary to run, and } \\
\text { the running status is controlled by the engine control unit. }\end{array}$ \\
\hline 7 & $\begin{array}{l}\text { Hybrid power } \\
\text { control unit }\end{array}$ & $\begin{array}{l}\text { Receives and processes a variety of external input signals, and in accordance } \\
\text { with the scheduled program, controls the frequency converter, engine control } \\
\text { unit, clutch and brake, enables the clutch and brake in different working } \\
\text { conditions, and uses the frequency converter and engine control unit to control } \\
\text { the corresponding actuators again. }\end{array}$ \\
\hline 8 & $\begin{array}{l}\text { Accelerator pedal } \\
\text { position sensor }\end{array}$ & $\begin{array}{l}\text { Provides the hybrid power control unit with the signal of whether to step down } \\
\text { the accelerator pedal and the extent of step. }\end{array}$ \\
\hline 9 & Brake switch & When braking, provide the hybrid power control unit with braking signal. \\
\hline 10 & Gear switch & $\begin{array}{l}\text { Provides the hybrid power control unit with gear information, including forward, } \\
\text { reversing and neutral position. }\end{array}$ \\
\hline 11 & Motor & $\begin{array}{l}\text { It is a permanent magnet brushless DC motor, and can drive wheels and start the } \\
\text { engine; it is controlled by the frequency converter, and the direction and speed of } \\
\text { the motor are controlled by controlling the phase sequence and frequency; the } \\
\text { frequency converter can also control the motor in the power generation mode, } \\
\text { and convert part of the vehicle's kinetic energy into electric energy, namely } \\
\text { "energy recovery". At the same time, the motor feeds back rotor position, motor } \\
\text { temperature and other technical parameters to the hybrid power control unit, so } \\
\text { that the hybrid power control unit controls the motor by frequency converter, and } \\
\text { if necessary, the protection mode can also be started. }\end{array}$ \\
\hline 12 & Brake & $\begin{array}{l}\text { Where a fixed gear ring is needed, the hybrid power control unit brakes the gear } \\
\text { ring by controlling the related electromagnetic valve to get through high pressure } \\
\text { oil path. }\end{array}$ \\
\hline 13 & Clutch 1 & $\begin{array}{l}\text { When it is essential to connect the engine output shaft and the gear ring into a } \\
\text { whole, the hybrid power control unit closes the clutch by controlling the related } \\
\text { electromagnetic valve to get through high pressure oil path. }\end{array}$ \\
\hline 14 & Clutch 2 & $\begin{array}{l}\text { When it is essential to connect the gear ring and planet carrier into a whole, the } \\
\text { hybrid power control unit closes the clutch by controlling the related } \\
\text { electromagnetic valve to get through high pressure oil path. }\end{array}$ \\
\hline 15 & $\begin{array}{l}\text { One-row planet } \\
\text { gear mechanism }\end{array}$ & $\begin{array}{l}\text { Composed of sun gear, gear ring and planet carrier, and realize the power } \\
\text { transfer, interruption and different transmission ratio through different } \\
\text { connections and constraints. }\end{array}$ \\
\hline 16 & Main reducer & Reduces the speed and increases the torque. \\
\hline 17 & $\begin{array}{l}\text { Differential } \\
\text { mechanism }\end{array}$ & $\begin{array}{l}\text { Enables the left and right wheels to rotate at different speeds, in order to adapt to } \\
\text { different road conditions and rotating needs. }\end{array}$ \\
\hline 18 & Wheels & Provide the vehicle on the ground with driving force and braking force. \\
\hline 19 & CAN bus & nposed of CAN - H and CAN - L, and used for data communications \\
\hline
\end{tabular}




\begin{tabular}{|c|c|l|}
\hline 20 & Ignition lock & $\begin{array}{l}\text { the engine control unit and hybrid power control unit. } \\
\text { lockides the hybrid power control unit with working signal. When the ignition }\end{array}$ \\
\hline 21 & $\begin{array}{c}\text { Charging } \\
\text { interface }\end{array}$ & $\begin{array}{l}\text { When it is needed and conditions permit, an external 220V AC power supply is } \\
\text { connected to recharge the power battery. }\end{array}$ \\
\hline 22 & Speed sensor & $\begin{array}{l}\text { Provides the hybrid power control unit with speed signal, and control the speed } \\
\text { when the vehicle speed is too high. }\end{array}$ \\
\hline 23 & $\begin{array}{c}\text { Engine auxiliary } \\
\text { control switch }\end{array}$ & $\begin{array}{l}\text { There are two kinds of working states, ignition and starting, to be used when the } \\
\text { engine is maintained or debugged. }\end{array}$ \\
\hline
\end{tabular}

\section{Working Principle and Working Process}

When the ignition lock is closed, the hybrid electric vehicle is working. When the gear switch is in the neutral position, the engine and motor don't work, both of the clutches are in the separated state, and the brake does not brake. After the gear switch is put into gear, the hybrid power control unit determines the working condition of the clutches and brakes through the analysis and calculation according to the signals from the accelerator pedal, gear, brake, speed and other sensors, and whether the motor and engine are working and their working mode. The working conditions, working modes and switching of various executing parts are automatically controlled, which also determines the working state of the hybrid electric vehicle [3].

Starting Condition. In the pure electric mode, the engine does not work, both the clutch 1 and the clutch 2 are in the separated state, and the brake acts on the gear ring. After being put into forward gear, the motor drives forward the vehicle to start and drive forward, and after being put into reverse gear, the motor reversely drives the vehicle to start and drive reversely.

Low Speed and Small Load Condition. In the pure electric mode, the engine does not work, the clutch 1 is in the separated state. According to the speed and driving resistance, there are two kinds of running modes, that is, the low gear mode is used when the resistance is large and the speed is relatively low, and the high gear mode is adopted at the time of small resistance and relatively high speed. (1) In the low gear mode, the clutch 2 is in the separated state, and the brake will brake the gear ring. (2) In the high gear mode the clutch 2 is in the closed state, and the brake does not brake the gear ring. After being put into forward gear, the motor drives forward the vehicle to drive forward, and after being put into reverse gear, the motor reversely drives the vehicle to drive reversely.

Medium and High Speed and Heavy Load Condition. This condition is only used in the forward driving state. In the process of driving the vehicle forward, the hybrid power control unit controls the clutch 1 and the clutch 2 in the closed state according to the status of each sensor signal timely, while the brake does not work and the motor starts the engine. After the engine starts successfully, there are two kinds of running modes: hybrid power mode and pure engine working mode [4]. (1) In the hybrid power mode, the clutch 2 is in the separated state, the clutch 1 is in the closed state, the brake does not work, and the engine and motor are at different rotation speeds and working status to drive the vehicle, thus to realize stepless variable speed. (2) When the power battery has low electric quantity, the running mode automatically switches to the pure engine working mode; at this time, the clutch 1 and the clutch 2 are in the closed state, the brake does not work and the vehicle is driven by the engine; when the engine has extra power, the motor turns into a generator, to recharge the power battery; otherwise, the motor is in the idling condition.

Reversing Condition. In the pure electric operating mode, the engine does not work, and the clutch 1 is in the separated state. According to the speed and driving resistance there are two kinds of running modes, namely, the low gear mode is used when the resistance is large and the speed is relatively low, and the high gear mode is adopted at the time of small resistance and relatively high speed. (1) In the low gear mode, the clutch 2 is in the separated state, and the brake will brake the gear ring. (2) In the high gear mode the clutch 2 is in the closed state, and the brake does not brake the gear ring. 
Sharp Deceleration, Braking and Over speeding Conditions when Driving Forward. When the vehicle in the process of forward driving is urgently decelerated, braked or the speed is more than the set top speed, the system's working mode will automatically switch to the mode of energy recovery; at this point, the engine does not work, the motor turns into a generator, and the vehicle's kinetic energy is converted into electric energy to recharge the battery. There are three kinds of modes: engine braking mode, low motor speed mode and high motor speed mode. (1) In the engine braking mode, the clutch 1 and clutch 2 are in the closed state, and the brake fails in braking; in addition to the energy recovery, the resistance of the motor can also be used to control the speed. (2) In the low speed mode, the clutch 2 is in the closed state, the clutch 1 is in the separated state and the brake fails in braking, and the motor speed is relatively low. (3) In the high speed mode, the clutch 1 and clutch 2 are in the separated state, and the brake works and the motor speed is relatively high.

Engine Maintenance or Debugging Status. When the engine is required for maintenance or debugging, the gear switch should be placed on the neutral position, and the engine auxiliary control switch is operated; there are two kinds of working conditions. (1) When the engine auxiliary control switch is on the ignition position, the engine control unit enters into the working state, and the engine can be tested by use of multimeter and other relevant instruments; at this point, the ignition lock don't need to be closed. (2) When the ignition lock is closed and the engine auxiliary control switch is on the startup position, the hybrid power control unit controls the clutch 1 to be connected and the clutch 2 to be separated, the brake working, and the motor reversing; after the engine has started successfully, the engine auxiliary control switch goes back to the ignition position, and the clutches are not separated, the brake fails in braking, and the engine maintenance or debugging can be carried out at the time [5].

Power Battery Lack of Power Storage. In case that the charging conditions are ready, an external 220V AC power supply can be first connected to recharge the power battery, and the vehicle is operated after the power storage of the battery is enough. If the charging conditions do not allow, the vehicle being started in the process of forward driving is in the pure electric mode, and then it turns into the pure engine working mode; at this time, the clutch 1 and clutch 2 are in the closed state, and the brake fails in braking and the motor is driven by the engine; when the engine has extra power, the motor turns into a generator, to recharge the power battery; otherwise, the motor is under the idling condition; the vehicle is in the pure electric working mode while reversing [6].

Power Battery in Shortage of Power Storage. In case that the charging conditions are ready, an external 220V AC power supply can be first connected to recharge the power battery, and the vehicle is driven normally after the power storage of the battery is enough. If the charging conditions do not allow, start the engine, and only then put into forward gear for driving.

Start the Engine. The ignition lock is closed and the gear switch is on the neutral position, the engine auxiliary control switch is in the startup position, and the hybrid power control unit controls the clutch 1 to be connected and the clutch 2 to be separated, the brake working and the motor reversing; after the engine has started successfully, the engine auxiliary control switch goes back to the ignition position.

The Vehicle Starting and Driving. After the engine has started successfully, the gear switch is set to the forward position, and the running mode is the pure engine working mode; at this time, both the clutch 1 and the clutch 2 are in the closed state and the brake fails in braking, and the motor is driven by the engine; when the engine has extra power, the motor turns into a generator to recharge the power battery; otherwise, the motor is under the idling condition.

The system has the advantages of energy saving and environmental protection. There is only one motor that can drive, generate power and start the engine at the same time, so that the entire structure is simple. With no speed changer set separately, the one-row planet gear mechanism can give play to the function of stepless speed changer. The engine control unit and the hybrid power control unit can cooperate with each other, to achieve the best optimized working mode. 


\section{References}

[1] Chen Shehui, Structure and maintenance of hybrid electric vehicle [M] Beijing: China Labour \& Social Security Publishing House, 2013.

[2] Zhao Zhenning. Structure, principle and maintenance of hybrid electric vehicle [M] Beijing: Beijing Institute of Technology Press, 2015.

[3] Tan Kecheng, Wan Dong. Structure, principle and maintenance of hybrid electric vehicle [M] Beijing: Chemical Industry Press, 2016.

[4] Zhang Jinzhu. Structure, principle and maintenance of hybrid electric vehicle [M] Beijing: Chemical Industry Press, 2011.

[5] Wu Xingmin, Zhang Bo, Wang Yanguang. Structure, principle and maintenance of electric vehicle [M] Beijing: Beijing Institute of Technology Press, 2015.

[6] Li Wei. Structure, principle and troubleshooting of new energy vehicle [M] Beijing: Chemical Industry Press, 2015. 